\title{
PENGEMBANGAN BUSINESS INTELLIGENCE DASHBOARD UNTUK MONITORING AKTIVITAS PARIWISATA (STUDI KASUS: DINAS PARIWISATA PROVINSI BALI)
}

\author{
Evan Himawan Saragih ${ }^{* 1}$ I Putu Agung Bayupati², Gusti Agung Ayu Putri \\ 1,2,3 Universitas Udayana Badung \\ Email: 1evansaragih@student.unud.ac.id, ${ }^{2}$ bayupati@unud.ac.id, ${ }^{3}$ ayuputri@it.unud.ac.id \\ *Penulis Korespondensi
}

(Naskah masuk: 16 Juli 2020, diterima untuk diterbitkan: 15 November 2021)

\begin{abstract}
Abstrak
Bali merupakan satu dari beberapa destinasi wisata yang mendatangkan wisatawan nusantara dan mancanegara di Indonesia. Pada tahun 2017, wisatawan mancanegara yang berkunjung ke Bali adalah sebesar 5,6 juta orang dan didominasi oleh wisatawan dari negara Cina. Jumlah kunjungan pada seluruh objek wisata yang ada di Bali tahun 2017 mencapai 17,8 juta kunjungan. Berdasarkan hal tersebut, pemerintah daerah membutuhkan strategi dan keputusan dalam pembangunan sarana dan prasarana yang dapat mendukung pengembangan dan kemajuan pariwisata di Bali. Pemanfaatan teknologi business intelligence dalam menganalisa data dalam jumlah yang besar akan membantu. Penelitian ini mengembangkan sistem informasi memakai pendekatan BI dalam menganalisis data pariwisata Bali dan manajemen data dengan menggantikan pemakaian kertas menjadi media komputer sehingga data tidak hilang begitu saja, namun digunakan sebagai acuan saat menentukan keputusan. Dalam pengembangan sistem digunakan beberapa metode diantaranya framework Codeigniter dengan arsitektur web MVC (Model, View, Controller), OLAP (On-line Analytical Processing) untuk menampilkan visualisasi data, dan double exponential smoothing menampilkan hasil peramalan data pada periode berikutnya. Nilai error dari metode peramalan tersebut dapat dihitung menggunakan algoritma Mean Absolute Percentage Error. Agar dapat mengetahui tingkat pemanfaatan terhadap pengembangan sistem ini, maka digunakan metode black box testing, usability testing, dan user acceptance test untuk mengetahui kualitas dan fungsionalitas sistem dari segi input, output, dan penilaian oleh pengguna sistem. Penelitian ini memperlihatkan bahwa pemakaian teknologi BI tidak hanya mendukung pada perusahaan namun juga mendukung pada bidang pariwisata, pemerintahan dan layanan. Sistem yang dikembangkan dapat membantu proses pemantauan pariwisata dan pendukung dalam pengambilan keputusan.
\end{abstract}

Kata kunci: Bali, Dashboard, Business Intelligence, Visualisasi, Peramalan

\section{DEVELOPMENT OF BUSINEES INTELLIGENCE DASHBOARD FOR MONITORING OF TOURISM ACTIVITY (CASE STUDY: BALI PROVINCE TOURISM DEPARTMENT)}

\begin{abstract}
Bali is one of several tourist destinations that bring domestic and foreign tourists to Indonesia. In 2017, there were 5.6 million foreign tourists visiting Bali and dominated by tourists from China. The number of visits to all tourist objects in Bali in 2017 reached 17.8 million visits. Based on this, local governments need strategies and decisions in the development of facilities and infrastructure that can support the development and progress of tourism in Bali. The use of business intelligence technology in analyzing large amounts of data will help. This study develops an information system using the BI approach in analyzing Bali tourism data and data management by replacing paper use as computer media so that data does not just disappear, but is used as a reference when making decisions. In system development, several methods are used including the Codeigniter framework with the MVC web architecture (Model, View, Controller), OLAP (On-line Analytical Processing) to display data visualization, and double exponential smoothing to display the results of forecasting data in the next period. The error value of this forecasting method can be calculated using the Mean Absolute Percentage Error algorithm. In order to determine the level of utilization of this system development, black box testing, usability testing and user acceptance tests are used to determine the quality and functionality of the system in terms of input, output, and assessment by system users. This study shows that the use of BI technology is not only supportive of companies but also supports tourism, government and services. The system developed can assist the tourism monitoring process and support decision making.
\end{abstract}

Keywords: Bali Tourism, Dashboard, Business Intelligence, Visualization, Forecasting 


\section{PENDAHULUAN}

Sebagai salah satu destinasi wisata di Indonesia, Bali disebut primadona karena terkenal hingga ke luar Indonesia yang mendatangkan wisatawan tidak hanya dari nusantara tetapi juga wisatawan mancanegara. Keunikan budaya, adat istiadat, kesenian, serta keindahan alam yang memesona menjadi daya tarik wisata yang memukau wisatawan membuat Bali disebut sebagai The Last Paradise. Tujuan wisatawan berkunjung ke Bali diantaranya adalah untuk rekreasi, binsis, dan MICE (Meeting, Incentive, Conference, Exhibiton). Fasilitas pendukung kepariwisataan seperti sarana transportasi, akomodasi, dan restoran diperlukan untuk mendorong kegiatan wisatawan saat melakukan kunjungan (Yoeti, 1990).

Sebuah institusi mampu menentukan keputusan secara cepat dan tepat dengan Business Intelligence. Aplikasi Business Intelligence menghasilkan analisis data di masa lalu dan memanfaatkan pengetahuan dari hasil analisis untuk mendukung keputusan dan perencanaan pada sebuah institusi (Arifin, 2014). Pemanfaatan business intelligence dalam melakukan analisis data dalam jumlah yang besar, sangat efektif dipakai untuk mengetahui keadaan perusahaan sehingga menghasilkan informasi yang berguna bagi setiap penggunanya (stakeholders) yaitu manajemen, staf, konsumen, mitra bisnis, pemilik perusahaan, dan pihak lain yang bersangkutan (Kao et al., 2016).

Metode pendekatan analisis data (Online Analytical Processing atau OLAP) terdapat dalam Business Intelligence. Dampak positif penerapan Business Intelligence Dashboard dengan pendekatan OLAP adalah mengumpulkan data, merapikan data, melakukan analisis data dan mengatur akses ke data sehingga memberi pengetahuan kepada pengguna dalam menentukan tindakan secara akurat dan cepat menggunakan OLAP.

Berdasarkan penelitian terdahulu yang dilakukan oleh Setiawan, Hendrawan dan Tyasnurita (2013) bahwa pengembangan teknologi business intelligence dashboard membuat proses yang sebelumnya panjang menjadi lebih efektif dan memudahkan dalam analisis karena data disajikan dalam bentuk visualisasi dashboard. Selanjutnya penelitian oleh Martiadi, Pudjiantoro dan Renaldi (2017) mengemukakan business intelligence adalah salah satu bentuk penerapan teknologi informasi dalam kegiatan mengumpulkan data, mengatur akses, serta melakukan analisis data dan informasi mengenai pencapaian perusahaan. Penerapan business intelligence di Bank $\mathrm{ABC}$ memberikan kemudahan dalam menganalisis berbagai produk bank yang ditawarkan, laporan disajikan dengan cepat dan interaktif sehingga keputusan pengembangan produk bank dapat diimplementasikan dengan cepat dan akurat (Prayitno, 2018).

Berdasarkan hasil plot data pariwisata Provinsi Bali yang akan dipakai dalam penelitian ini maka diketahui data memiliki pola data stasioner, tidak stasioner, dan mengandung trend di dalamnya. Metode forecasting yang dipakai dalam penelitian ini adalah double exponential smoothing. Metode smoothing digunakan untuk memperkecil inkonsistensi data yang bersifat musiman dengan cara membuat rata-rata dari masa lampau menjadi seimbang (Raftery, 1985).

Tujuan penelitian ini adalah merancang sistem Business Intelligence Dashboard yang berfungsi sebagai alat monitoring aktivitas pariwisata Bali dengan menggantikan pemakaian kertas menjadi media komputer dan manajemen data agar data tidak hilang begitu saja, namun digunakan untuk mendukung pengambilan keputusan. Business intelligence akan dipakai dalam pengolahan, analisis, dan publikasi data pada kegiatan parawisata yang dilakukan. Fokus penelitian ini yakni data jumlah wisatawan, jumlah penumpang, jumlah akomodasi, restoran, bar, dan objek wisata yang diolah oleh Dinas Pariwisata Provinsi Bali. Data akan dianalisis memakai pendekatan business intelligence agar mampu menyediakan informasi yang diperlukan sebagai pendukung dalam pengambilan keputusan.

\section{METODE PENELITIAN}

Bagian ini berisi pembahasan mengenai teoriteori yang menjadi dasar dalam pembuatan penelitian ini.

\subsection{Metode Penelitian}

Alur penelitian terdiri dari langkah-langkah yang dipakai dalam pembuatan sistem pada penelitian ini. Pembuatan sistem ini dibagi kedalam beberapa tahapan.

\section{1) Tahapan Persiapan}

Aktivitas yang dilaksanakan pada tahap ini mencakup pengumpulan gagasan (brainstorming). Langkah beriktunya adalah merumusan masalah dan menetapkan tujuan penelitian. Setelah itu, melakukan studi literatur berkaitan dengan pengkajian pustakapustaka dari literatur buku, jurnal maupun pustaka lain yang relevan. Pembahasan literatur dalam penelitian ini yaitu Business Intelligence, Online Analytical Processing, dan Double Exponential Smoothing. Pada studi lapangan dilakukan pengamatan mengenai bisnis proses yang dijalankan oleh Dinas Pariwisata Provinsi Bali.

\section{2) Tahap Pengumpulan Data}

Pada penelitian ini dilakukan pengumpulan data sebagai bahan penelitian diantaranya data jumlah penumpang melalui Bandara Internasional I Gusti Ngurah Rai tahun 2000-2019, data jumlah penumpang melalui Pelabuhan Ketapang-Gilimanuk tahun 2000-2019, data jumlah penumpang melalui Pelabuhan Lembar-Padang Bai tahun 2000-2019, data kedatangan wisatawan mancanegara yang langsung ke Bali berdasarkan kebangsaan setiap bulan tahun 2000-2018, data restoran/rumah makan di Provinsi Bali per kabupaten/kota tahun 2016-2019, 
data bar di Provinsi Bali per kabupaten/kota tahun 2016-2019, data akomodasi di Provinsi bali per kabupaten/kota tahun 2016-2019, data perkembangan kunjungan wistawan pada Kawasan objek dan daya tarik wisata di Bali tahun 2000-2017. Sebagian besar data yang didapat masih berbentuk buku statistik, sehingga dilakukan tabulasi data secara manual.

\section{3) Tahap Pemrosesan Data}

Pada tahap ini merancang antarmuka untuk mempermudah user dalam berinteraksi dengan sistem, merancang database, diagram konteks, data flow diagram, implementasi metode OLAP terhadap visualisasi statistik pariwisata, dan implementasi metode peramalan regresi linear, single exponential smoothing, double exponential smoothing terhadap peramalan jumlah penumpang melalui Bandara Internasional I Gusti Ngurah Rai, jumlah penumpang melalui Pelabuhan Ketapang-Gilimanuk, jumlah penumpang Pelabuhan Lembar-Padang Bai, jumlah restoran/rumah makan di Provinsi Bali, jumlah bar di Provinsi Bali, jumlah akomodasi di Provinsi Bali, dan Perkembangan kunjungan wisatawan pada kawasan objek dan daya tarik wisata di Bali.

\section{4) Tahap Pengembangan Sistem}

Pada tahap ini mengimplementasikan sistem sesuai dengan rancangan yang telah dirancang ke dalam bahasa pemrograman. Output tahap ini adalah sistem yang dapat menampilkan visualisasi dan meramalkan jumlah penumpang melalui Bandara Internasional I Gusti Ngurah Rai, jumlah penumpang melalui Pelabuhan Ketapang-Gilimanuk, jumlah penumpang Pelabuhan Lembar-Padang Bai, jumlah restoran/rumah makan di Provinsi Bali, jumlah bar di Provinsi Bali, jumlah akomodasi di Provinsi Bali, dan Perkembangan kunjungan wisatawan pada kawasan objek dan daya tarik wisata di Bali menggunakan metode double exponential smoothing. Pada tahap ini juga dilakukan tahapan uji coba.

\section{5) Tahap Penarikan Kesimpulan}

Pada tahap menyimpulkan hasil penelitian dan saran atas keseluruhan penelitian yang dilakukan. Kesimpulan yang dihasilkan akan memberi jawaban atas tujuan pelaksanaan dilakukannya penelitian ini.

\subsection{Business Intelligence}

Business Intelligence dipakai dalam menyatukan, menyimpan, melakukan analisis, dan mengatur akses pada data agar dapat memberikan gambaran kepada pengguna saat menentukan langkah dengan lebih baik dan tepat (Brannon, 2010).

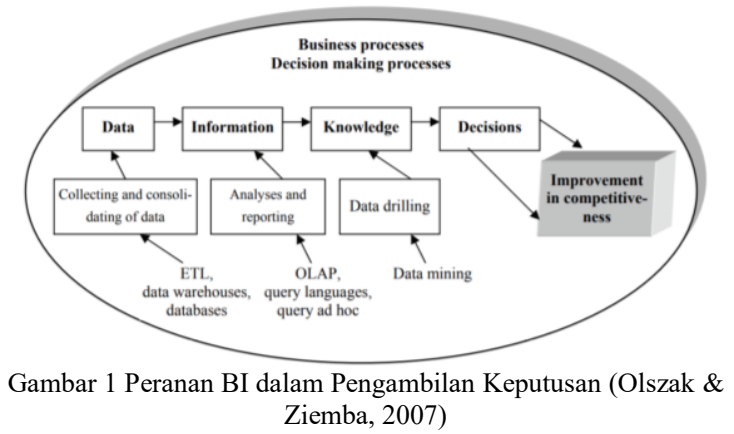

Gambar 1 merupakan proses pengambilan keputusan dengan BI. Pengambilan keputusan membutuhkan data dari sistem business intelligence yang bersumber dari kumpulan data factual, data perencanaan, maupun data prediksi yang dikelola menjadi informasi yang luas, lengkap, dan biasanya menghasilkan perbandingan sehingga dapat memberikan analisis. Penggunaan sistem business intelligence diharapkan dapat menentukan keputusan dengan cepat dan tegas serta dapat mengambil keputusan dengan resiko yang lebih kecil.

\subsection{Forecasting (Peramalan)}

Peramalan (forecasting) merupakan metode dalam membuat estimasi (perkiraan) data periode yang akan datang dengan menjadikan penggunaan data periode lampau dalam suatu bentuk model matematis (Mahbub, Paul \& Azeem 2013). Dalam setiap pengambilan keputusan, peramalan menjadi bagian penting bagi sebuah organisasi bisnis. Peramalan dapat dijadikan dasar dalam perencanaan jangka pendek, menengah maupun jangka panjang suatu organisasi.

Salah satu metode untuk peramalan adalah pemulusan eksponensial ganda (double exponential smoothing/DES). Metode ini dapat diimplementasikan pada pola data yang memuat trend. Metode ini dikemukakan oleh Brown (Makridakis, Wheelwright C \& McGee 1999).

Konstanta pemulusan yang ditetapkan akan mempengaruhi akurasi hasil prediksi pada metode exponential smoothing (Azu, 2014). Pendekatan memilih nilai $\alpha$ dapat ditentukan berdasarkan ukuran perhitungan kesalahan peramalan yang dipakai. Alhasil, nilai-nilai peramalan akan sangat beragam berdasarkan nilai-nilai $\alpha$ yang dipakai.

$$
\begin{gathered}
S_{t}^{\prime}=\alpha \cdot X_{t}+(1-\alpha) S_{t-1}^{\prime} \\
S_{t}^{\prime \prime}=\alpha \cdot S_{t}^{\prime}+(1-\alpha) S_{t-1}^{\prime \prime} \\
a_{t}=2 \cdot S_{t}^{\prime}-S_{t}^{\prime \prime} \\
b_{t}=\frac{\alpha}{1-\alpha}\left(S_{t}^{\prime}-S_{t}^{\prime \prime}\right)
\end{gathered}
$$




$$
\begin{gathered}
F_{t+m}=a_{t}+b_{t} \cdot m \\
M A P E=\frac{1}{n} \sum_{t=1}^{n} \frac{\left|A_{t}-F_{t}\right|}{A_{t}} * 100
\end{gathered}
$$

Dimana:

$S_{t}^{\prime} \quad=$ pemulusan tunggal periode ke- $t$

$S_{t}^{\prime \prime} \quad=$ pemulusan ganda periode ke- $t$

$X_{t} \quad=$ nilai aktual pada periode ke- $t$ $\alpha \quad=$ konstanta pemulusan $(0<\alpha<1)$

$a_{t} \quad=$ nilai konstanta pada periode ke- $t$

$b_{t} \quad=$ nilai konstanta pada periode ke- $t$

$F_{t+m}=$ nilai peramalan periode berikutnya

$m \quad=$ jangka waktu permalan

$n \quad$ = banyak periode

$A_{t} \quad=$ nilai aktual periode ke- $t$

$F_{t} \quad=$ nilai peramalan periode ke- $t$
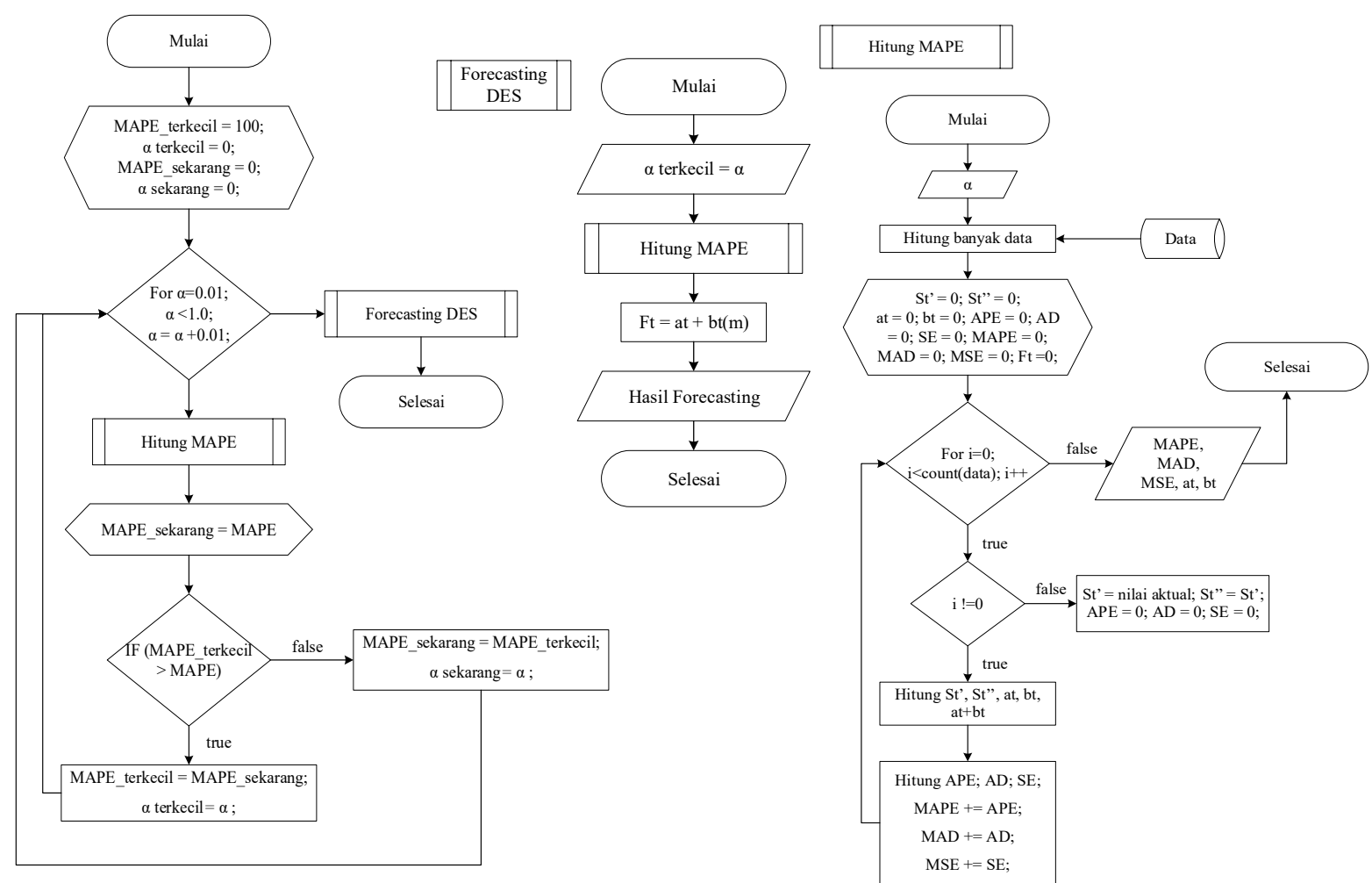

Gambar 2 Flowchart Perhitungan Peramalan dengan Metode Double Exponential Smoothing (DES)

Flowchart peramalan metode double exponential smoothing (DES) terdapat pada gambar 2. Berikut ini adalah langkah-langkah proses peramalan dengan metode double exponential smoothing (DES).

1) Insialisasi variabel yang digunakan sebagai tempat pengolahan.

2) Perulangan nilai $\alpha$. Dimana apabila nilai $\alpha$ lebih kecil dari 1 maka perulangan akan terus berlanjut hingga $\alpha$ memenuhi syarat perulangan.

3) Mengambil data yang ada pada database, kemudian dihitung banyaknya jumlah data.

4) Apabila $\alpha$ belum memenuhi syarat maka akan mencari nilai smoothing pertama (S't), smoothing kedua (S't) nilai at, nilai bt, at ditambah bt menggunakan Persamaan 1 untuk smoothing pertama, Persaman 2 untuk smoothing kedua, Persamaan 3 untuk at, Persamaan 4 untuk bt, Persamaan 6 untuk MAPE melalui sub proses Hitung MAPE.
5) Menghitung nilai MAPE terkecil. Apabila telah ditemukan MAPE_terkecil maka proses perulangan mencari $\bar{M} A P E$ terkecil berhenti dan ditemukan nilai $\alpha$ (konstanta pemulusan) lewat MAPE terkecil.

6) Setelah mendapatkan nilai $\alpha$ dengan MAPE terkecil, maka dilakukan perhitungan peramalan kembali dengan menggunakan Persamaan 5.

7) Output dari flowchart ini adalah nilai peramalan (y) dan nilai MAPE

\subsection{OLAP}

OLAP (Online Analytical Processing) merupakan teknologi dibalik aplikasi Business Intelligence (BI). OLAP memiliki kemampuan untuk melakukan perhitungan analitik yang rumit dan perencanaan skenario seperti anggaran ataupun prediksi. Online Analytical Processing adalah kombinasi dinamis analisis dan gabungan dari data multidimensional dalam jumlah yang besar (Connolly \& Begg, 2015). 


\subsection{Black Box Testing}

Uji coba dengan black box testing dilakukan oleh pengembang sistem berdasarkan spesifikasi sistem. Selain itu, black box testing akan melakukan dengan memasukkan berbagai macam masukan dan memeriksa keluaran yang dihasilkan. Metode ini dilakukan agar dapat mengetahui apakah fungsionalitas dapat menerima input yang tidak diharapkan (Mustaqbal, Firdaus \& Rahmadi, 2015).

\subsection{User Acceptance Test}

UAT (user acceptance test) adalah suatu proses uji coba oleh pengguna yang ditujukan untuk dokumen yang dipakai sebagai pernyataan bahwa perangkat lunak yang dikembangkan telah dapat diterima oleh pengguna. Uji coba yang dilakukan menjadi acuan apakah sistem telah dapat diterima oleh pengguna (Cimperman, 2006).

\section{PERANCANGAN SISTEM}

Bagian ini berisi analisa kebutuhan sistem, desain diagram kelas, dan perancangan BI dashboard.

\subsection{Analisa Kebutuhan Sistem}

Sistem yang dikembangkan pada penelitian ini digunakan untuk membantu melakukan monitoring aktivitas pariwisata di Provinsi Bali. Informasi kebutuhan fungsional yang harus dimiliki oleh sistem yang dikembangkan dapat dilihat pada gambar 4 yang menggambarkan use case dari sistem .

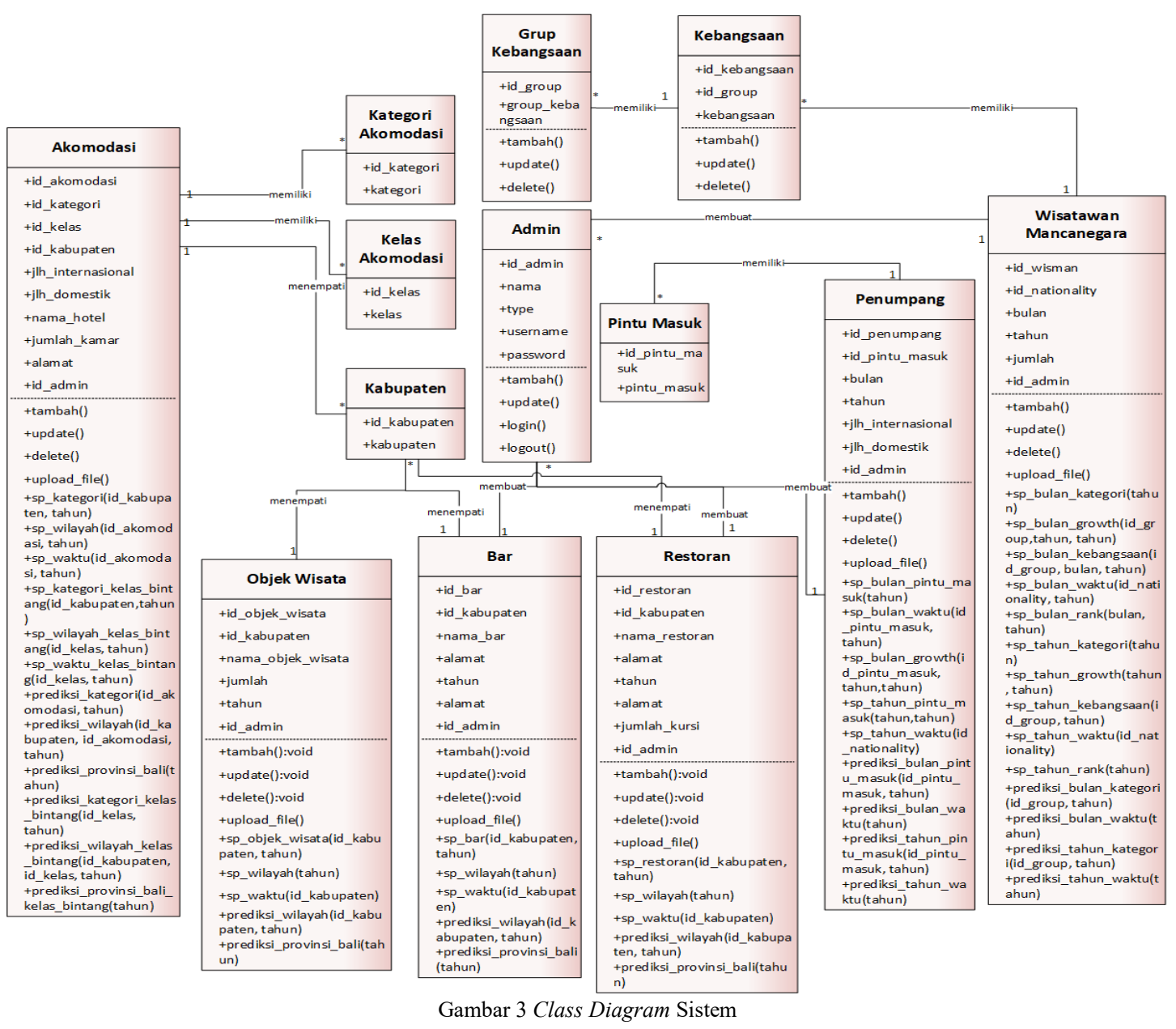

Berikut kebutuhan fungsional pada sistem:

1) Fitur pengelolaan data pariwisata Provinsi Bali. Pada bagian ini dapat dilakukan manipulasi data jumlah penumpang, wisatawan mancanegara, akomodasi, restoran, bar, objek wisata, grup kebangsaan, kebangsaan, dan pintu masuk.

2) Fitur manajemen admin adalah fasilitas atau layanan yang disediakan untuk dapat mengatur admin. Pembuatan admin dilakukan agar dapat melakukan pengelolaan data pariwisata Provinsi Bali.
3) Fitur Statistik Data. Pada fitur ini, user maupun admin dapat melihat hasil pengelolaan data lewat beberapa bentuk chart yang mempermudah analisa data.

4) Fitur Prediksi Data. Dihadirkan untuk membantu user terutama yang bergerak dalam bidang pariwisata untuk dapat melihat peramalan situasi pariwisata di masa yang akan datang. Prediksi yang dihasilkan dapat menghasilkan peramalan lima periode mendatang. 


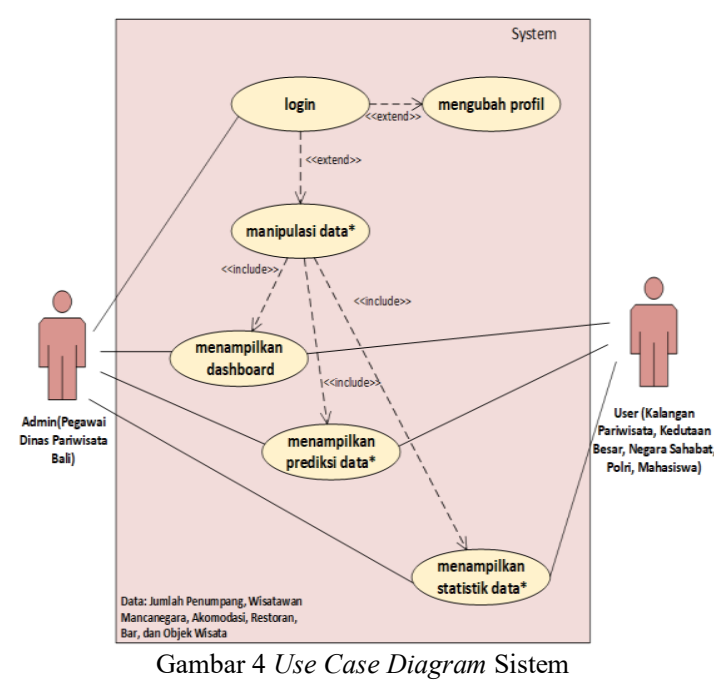

\subsection{Design Class Diagram}

Gambar 3 adalah kelas-kelas yang diimplementasikan dalam pembuatan database pada penelitian ini meliputi class Admin (pegawai dinas pariwisata Provinsi Bali) yang memiliki atribut dan operation yang berperan sebagai aktor dalam sistem. Terdapat juga class Penumpang, Wisatawan_Mancanegara, Akomodasi, Restoran, Bar, Objek_Wisata, Grup_Kebangsaan, Kebangsaan, Kabupaten, Kategori_Akomodasi, Kelas_Akomodasi, dan Pintu_Masuk. Class Penumpang memiliki relasi asosiasi dengan class Pintu_Masuk dan class Admin. Class Wisatawan Mancanegara memiliki relasi asosiasi dengan class Kebangsaan dan class Admin.

Class Akomodasi memiliki relasi asosiasi dengan class Kategori_Akomodasi, class Kelas_Akomodasi, dan class Admin. Class Restoran memiliki relasi asosiasi dengan class Kabupaten dan class Admin. Class Bar memiliki relasi asosiasi dengan class Kabupaten dan class Admin. Class Objek_Wisata memiliki relasi asosiasi dengan class Kabupaten dan class Admin. Class Kebangsaan memiliki relasi asosiasi dengan class Grup_Kebangsaan.

Pada penelitian ini terdapat dua aktor yaitu Admin (pegawai dinas pariwisata Provinsi Bali) dan User (Kalangan Pariwisata, Kedutaan Besar, Negara Sahabat, Polri, dan Mahasiswa). Aktivitas yang bisa dilakukan admin meliputi login, dimana dengan kegiatan login tersebut admin dapat melakukan mengubah profil dan manipulasi data jumlah penumpang, wisatawan mancanegara, akomodasi, restoran, bar, objek wisata, kebangsaan, dan grup kebangsaan. Seorang user hanya dapat melihat statistik dan prediksi jumlah penumpang, wisatawan mancanegara, akomodasi, restoran, bar, dan objek wisata. Setiap data dapat diakses oleh user apabila data telah dimasukkan oleh admin.

\subsection{Perancangan BI Dashboard}

Sistem yang akan diimplementasikan berfokus pada visualisasi dan peramalan data pariwisata Provinsi Bali. Inti penelitian dibatasi menjadi kebutuhan fungsional dari pengembangan Business Intelligence Dashboard.

Untuk dapat mengakses sistem tidak membutuhkan login, namun untuk dapat melakukan manajemen data membutuhkan proses login terlebih dahulu. Pengguna dapat menentukan daftar maupun fungsi-fungsi yang merupakan fitur yang dirancang pada halaman dashboard. Secara umum fitur-fitur yang dirancang pada penelitian ini dapat dilihat pada Tabel 1.

\begin{tabular}{|c|c|}
\hline Fitur & Keterangan \\
\hline Login, Logout & $\begin{array}{l}\text { Membatasi akses sistem pada manajemen } \\
\text { data }\end{array}$ \\
\hline Dashboard & $\begin{array}{l}\text { Menampilkan visualisasi data jumlah } \\
\text { penumpang, wisatawan mancanegara, } \\
\text { akomodasi, restoran, bar, dan objek wisata }\end{array}$ \\
\hline Top 5 & Menampilkan 5 negara dengan kunjungan \\
\hline Wisatawan & wisata terbanyak ke Bali \\
\hline Mancanegara & \\
\hline $\begin{array}{l}\text { Top } 5 \text { Objek } \\
\text { Wisata }\end{array}$ & $\begin{array}{l}\text { Menampilkan } 5 \text { objek wisata di Bali } \\
\text { dengan pengunjung terbanyak }\end{array}$ \\
\hline Top 5 Restoran & $\begin{array}{l}\text { Menampilkan } 5 \text { kabupaten/kota di Bali } \\
\text { dengan jumlah restoran terbanyak }\end{array}$ \\
\hline Top 5 & Manampilkan 5 kabupaten/kota di Bali \\
\hline Akomodasi & dengan jumlah akomodasi terbanyak \\
\hline Top 5 Bar & $\begin{array}{l}\text { Manampilkan } 5 \text { kabupaten/kota di Bali } \\
\text { dengan jumlah bar terbanyak }\end{array}$ \\
\hline $\begin{array}{l}\text { Top } 5 \text { Hotel } \\
\text { Kelas Bintang }\end{array}$ & $\begin{array}{l}\text { Manampilkan } 5 \text { kabupaten/kota di Bali } \\
\text { dengan jumlah hotel kelas bintang } \\
\text { terbanyak }\end{array}$ \\
\hline Statistik & Menampilkan statistik dan visualisasi data \\
\hline Pariwisata & $\begin{array}{l}\text { jumlah penumpang, wisatawan } \\
\text { mancanegara, akomodasi, restoran, bar, } \\
\text { dan objek wisata }\end{array}$ \\
\hline Prediksi & $\begin{array}{l}\text { Menampilkan hasil prediksi data jumlah } \\
\text { penumpang, wisatawan mancanegara, } \\
\text { akomodasi, restoran, bar, dan objek wisata } \\
\text { menggunakan metode double exponential } \\
\text { smoothing. }\end{array}$ \\
\hline
\end{tabular}

\section{HASIL DAN PEMBAHASAN}

Hasil dari pengembangan sistem dituangkan dalam bentuk interface. Pengembangan Business Intelligence Dashboard berbasis web mencakup 4 bagian utama, yaitu bagian dashboard, bagian statistik pariwisata, bagian prediksi, dan bagian manajemen data.

Dashboard berfungsi untuk menampilkan informasi persentase perbandingan pada Gambar 5, visualisasi data pada Gambar 6, dan lima besar data wisatawan mancanegara, objek wisata, restoran, bar, akomodasi, dan hotel bintang pada Gambar 7 . 


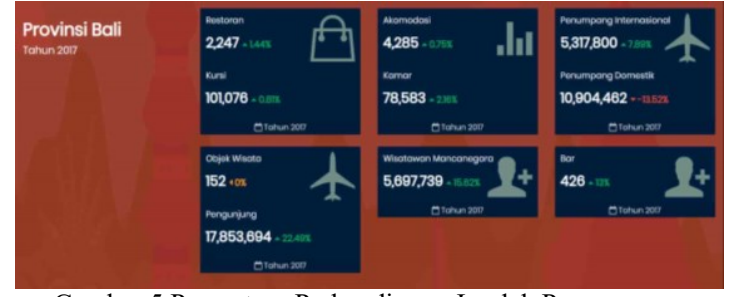

Gambar 5 Persentase Perbandingan Jumlah Penumpang, Akomodasi, Wisatawan Mancanegara, Restoran, Bar, dan Objek Wisata

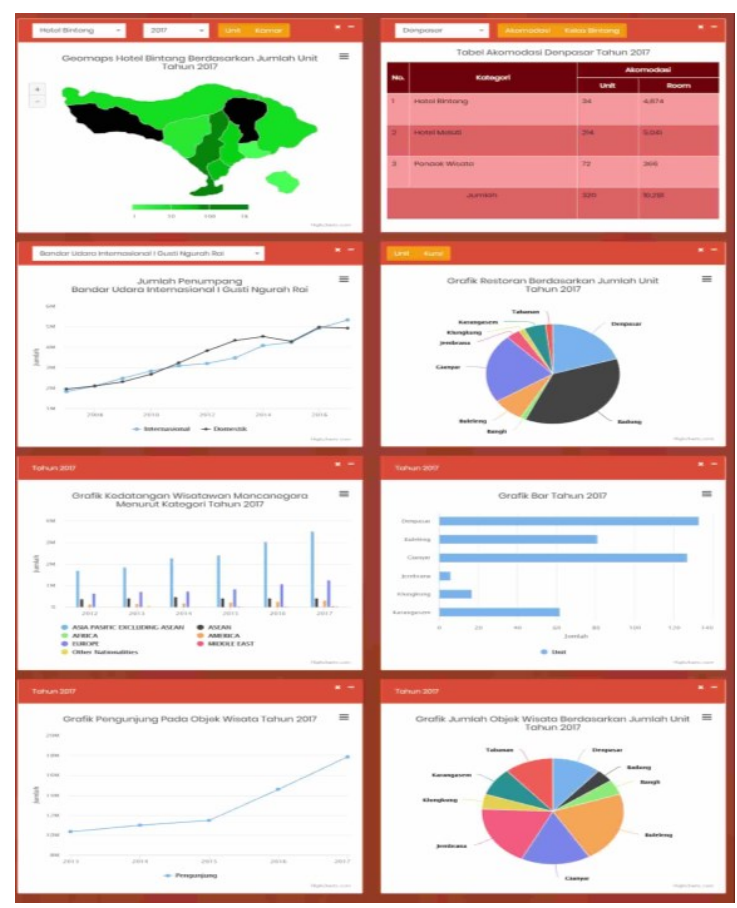

Gambar 6 Visualisasi data Jumlah Penumpang, Akomodasi, Wisatawan Mancanegara, Restoran, Bar, dan Objek Wisata

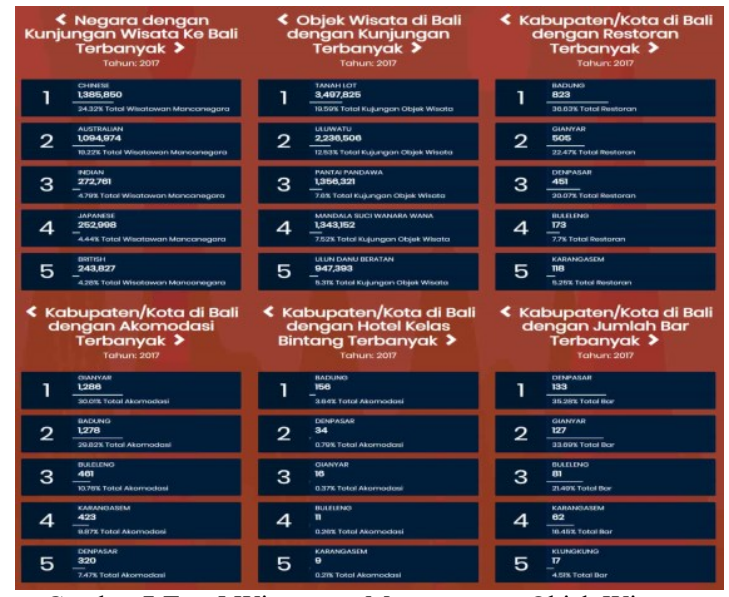

Gambar 7 Top 5 Wisatawan Mancanegara, Objek Wisata, Restoran, Akomodasi, Hotel Bintang, dan Bar

Statistik pariwisata berfungsi untuk menampilkan data pariwisata yaitu data jumlah penumpang, wisatawan mancanegara, akomodasi, bar, restoran, dan objek wisata secara lebih rinci dalam bentuk tabel, map, batang, dan area. Pengguna perlu menentukan data pariwisata yang akan dicari dan memilih keysearch sesuai dengan data pariwisata untuk dijadikan acuan dalam pencarian data pada database.

Prediksi menampilkan hasil prediksi data jumlah penumpang, wisatawan mancanegara, akomodasi, restoran, bar, dan objek wisata menggunakan metode double exponential smoothing dapat dilihat pada gambar 8. Pengguna hanya perlu menentukan data pariwisata yang akan dicari dan memilih keysearch sesuai dengan data pariwisata untuk dijadikan acuan dalam pencarian data pada database dan proses perhitungan peramalan.

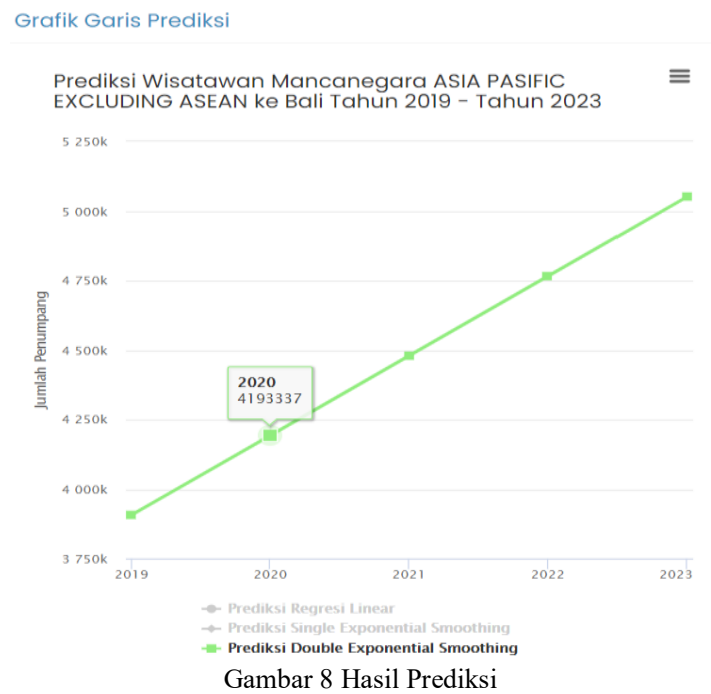

Langkah awal agar dapat mengakses fitur manajemen adalah melakukan proses login. Login dilakukan dengan memasukkan data pengguna berupa nama pengguna dan kata sandi yang terdaftar. Fitur ini berfungsi untuk mengolah data, seperti membuat dan memasukkan data baru, menyunting data, dan juga membuang data.

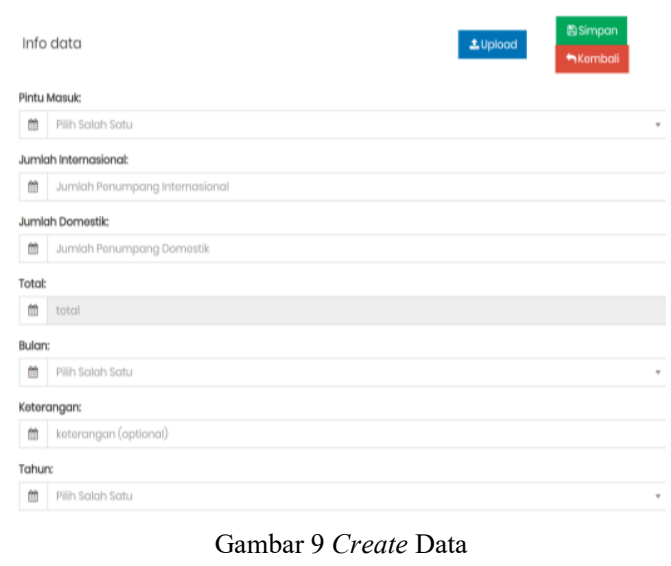

Gambar 9 adalah halaman tambah data. Pengguna dapat melihat data yang telah ditambahkan ke dalam database pada awal halaman. Menyimpan data dapat dilakukan dengan menekan tombol simpan data. Sukses atau tidak proses simpan data, sistem akan memberikan notifikasi. Pengguna juga dapat menambahkan data dengan menggunggah file excel. 
Form upload file dapat dilakukan dengan menekan tombol upload pada form input data.

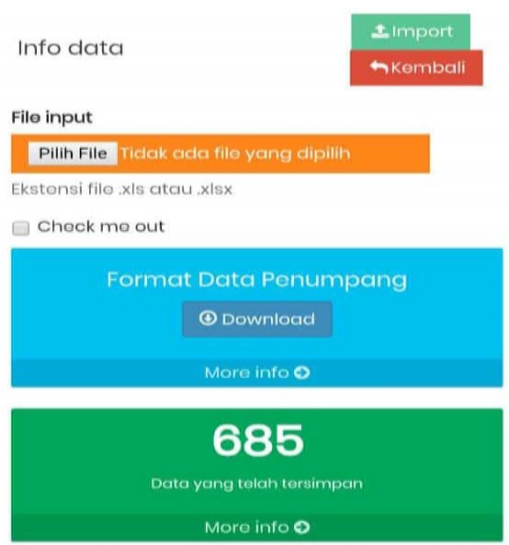

Gambar 10 Import Data

Gambar 10 adalah halaman import data. Pengguna dapat menggunggah file excel dengan mengikuti format data yang telah ditentukan. Pengguna dapat mengunduh format data yang telah disediakan. Selain itu pengguna dapat melihat jumlah data yang telah tersimpan pada database. Apabila akan menyimpan file yang telah diunggah ke dalam database maka menekan tombol upload. Gambar 11 Halaman edit data apabila pengguna ingin melakukan perbaikan pada data pariwisata yang sebelumnya telah diinputkan ke dalam database.

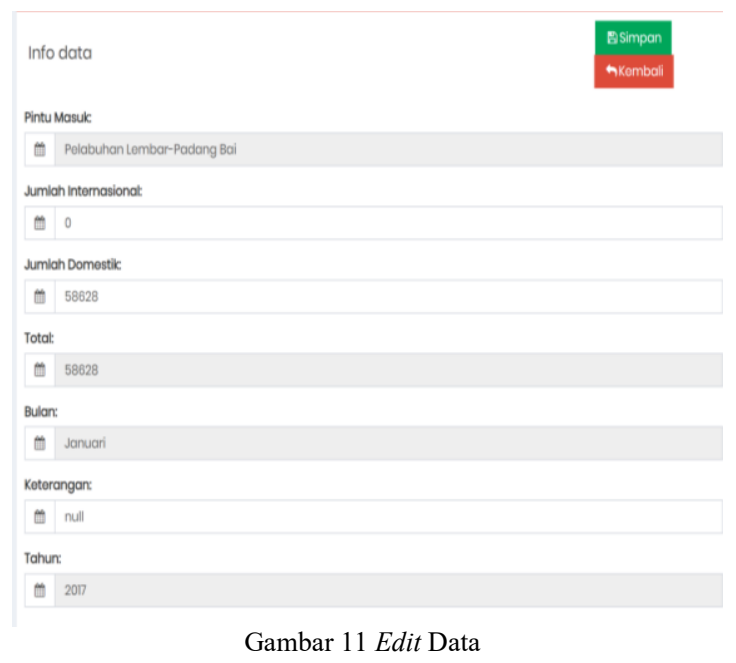

Pengguna dapat melakukan perbaikan pada data dengan menekan tombol detail pada halaman data pariwisata. Pengguna hanya dapat melakukan perbaikan pada kolom yang diizinkan. Apabila akan menyimpan data dapat dilakukan dengan menekan tombol simpan.

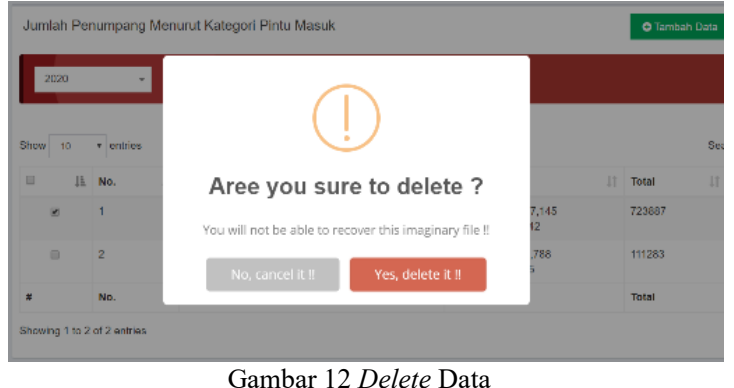

Gambar 12 merupkan halaman delete data. Pengguna dapat menghapus data yang tidak diperlukan lagi. Fitur delete data dapat diakses dengan menekan tombol checklist pada bagian kiri tabel kemudian menekan tombol hapus data. Apabila telah berhasil atau gagal menghapus data maka akan muncul notifikasi.

\section{PENGUJIAN SISTEM}

Pengujian sistem dengan Black Box Testing ditampilkan pada tabel 2. Pengujian fungsional interface sistem ditampilkan pada tabel 3.

\begin{tabular}{|c|c|c|c|}
\hline $\begin{array}{l}\text { No } \\
\text {. }\end{array}$ & Kasus Uji & Kondisi & Hasil \\
\hline 1. & Login & 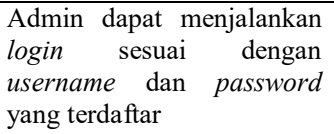 & Valid \\
\hline 2. & Profil & $\begin{array}{l}\text { Admin dapat mengganti } \\
\text { foto, username dan } \\
\text { password }\end{array}$ & Valid \\
\hline 3. & CRUD Bar & $\begin{array}{l}\text { Proses penambahan, } \\
\text { pengubahan, } \\
\text { penghapusan data bar }\end{array}$ & Valid \\
\hline 4. & Dashboard & $\begin{array}{l}\text { Menampilkan grafik jumlah } \\
\text { penumpang, grafik } \\
\text { akomodasi, grafik restoran, } \\
\text { grafik jumlah wisatawan } \\
\text { mancanegara, grafik bar, } \\
\text { grafik objek wisata, data } \\
\text { negara dengan kunjungan } \\
\text { wisata terbanyak ke Bali, } \\
\text { data objek wisata di Bali } \\
\text { dengan kunjungan } \\
\text { terbanyak, kabupaten/kota } \\
\text { di Bali dengan Restoran; } \\
\text { Hotel kelas bintang; Bar } \\
\text { terbanyak, }\end{array}$ & Valid \\
\hline 5. & $\begin{array}{l}\text { Statistik } \\
\text { Region }\end{array}$ & $\begin{array}{l}\text { Menampilkan } \\
\text { akomodasi, restoran, bar, } \\
\text { dan objek wisata } \\
\text { berdasarkan kabupaten/kota }\end{array}$ & Valid \\
\hline 6. & $\begin{array}{l}\text { Prediksi } \\
\text { Region }\end{array}$ & $\begin{array}{l}\text { Menampilkan prediksi data } \\
\text { akomodasi, restoran, bar, } \\
\text { dan objek wisata } \\
\text { berdasarkan kabupaten/kota }\end{array}$ & Valid \\
\hline
\end{tabular}

Tabel 2 adalah pegujian black box. Pada pengujian ini tidak ditemukan adanya error pada setiap pengujian fungsional. Pengujian yang melibatkan evaluasi antarmuka sesuai dengan 10 prinsip usability heuristic evaluation yang dikemukakan oleh Jacob Nielsen membuat beberapa hasil evaluasi dapat dilihat pada tabel 3 . 
Tabel 3 Heuristic Testing

\begin{tabular}{|c|c|c|c|}
\hline No. & Prinsip & Ada? & Bagaimana? \\
\hline 1. & $\begin{array}{l}\text { Visibility } \\
\text { Of System } \\
\text { Status }\end{array}$ & $\mathrm{Ya}$ & $\begin{array}{l}\text { Sistem sudah memberikan } \\
\text { umpan balik dalam } \\
\text { pemberian warna font ketika } \\
\text { memilih menu navigasi. }\end{array}$ \\
\hline 2. & $\begin{array}{l}\text { Match } \\
\text { between } \\
\text { system and } \\
\text { realworld }\end{array}$ & $\mathrm{Ya}$ & $\begin{array}{l}\text { Sistem sudah menggunakan } \\
\text { bahasa sehari-hari. }\end{array}$ \\
\hline 3. & $\begin{array}{l}\text { User } \\
\text { Control } \\
\text { and } \\
\text { Freedom }\end{array}$ & $\mathrm{Ya}$ & $\begin{array}{l}\text { User admin dapat melakukan } \\
\text { penambahan, penghapusan, } \\
\text { dan perubahan data namun } \\
\text { belum terdapat suatu fungsi } \\
\text { yang dapat mengembalikan } \\
\text { data yang sudah dihapus. }\end{array}$ \\
\hline 4. & $\begin{array}{l}\text { Error } \\
\text { Prevention }\end{array}$ & $\mathrm{Ya}$ & $\begin{array}{l}\text { Pada saat melakukan } \\
\text { penambahan data, form } \\
\text { menampilkan contoh jenis } \\
\text { teks yang akan diinputkan ke } \\
\text { dalam database. Selain itu } \\
\text { akan diberikan } \text { alert } \text { apabila } \\
\text { inputan tidak sesuai. }\end{array}$ \\
\hline 5. & $\begin{array}{l}\text { Consistenc } \\
y \text { and } \\
\text { Standard }\end{array}$ & $\mathrm{Ya}$ & $\begin{array}{l}\text { Tata letak halaman web } \\
\text { sebagian besar adalah sama. }\end{array}$ \\
\hline 6. & $\begin{array}{l}\text { Recognitio } \\
\text { nrather } \\
\text { than Recall }\end{array}$ & $\mathrm{Ya}$ & $\begin{array}{llr}\text { Tidak perlu mengingat } \\
\text { langkah sebelumnya untuk } \\
\text { dapat mengakses suatu } \\
\text { halaman karena sudah menu } \\
\text { navigasi sudah disesuaikan } \\
\text { dengan fungsinya. }\end{array}$ \\
\hline 7. & $\begin{array}{l}\text { Flexibility } \\
\text { and } \\
\text { efficiency } \\
\text { of use }\end{array}$ & $\mathrm{Ya}$ & $\begin{array}{l}\text { Dalam menambah data pada } \\
\text { sistem, user dapat } \\
\text { menggunakan upload file } \\
\text { untuk mempermudah } \\
\text { menambah data. }\end{array}$ \\
\hline
\end{tabular}

\begin{tabular}{|c|c|c|c|}
\hline No. & Prinsip & Ada? & Bagaimana? \\
\hline 8. & $\begin{array}{l}\text { Aesthetic } \\
\text { and } \\
\text { minimalist } \\
\text { design }\end{array}$ & $\mathrm{Ya}$ & $\begin{array}{l}\text { Desain halaman sebagain } \\
\text { besar dengan latar belakang } \\
\text { putih untuk mempermudah } \\
\text { penglihatan dipadukan } \\
\text { dengan warna left bar dan } \\
\text { header dengan warna gelap } \\
\text { sebagai pembeda. }\end{array}$ \\
\hline 9. & $\begin{array}{l}\text { Help users } \\
\text { recognize, } \\
\text { diagnose, } \\
\text { and } \\
\text { recover } \\
\text { from errors }\end{array}$ & Ya & $\begin{array}{ll}\text { Muncul alert } & \text { atau } \\
\text { pemberitahuan ketika } & \text { user } \\
\text { memasukkan inputan } & \text { yang } \\
\text { tidak sesuai. } & \end{array}$ \\
\hline 10. & $\begin{array}{l}\text { Help and } \\
\text { documentat } \\
\text { ion }\end{array}$ & $\mathrm{Ya}$ & $\begin{array}{l}\text { Tersedia petunjuk bagaimana } \\
\text { cara mengunggah file melalui } \\
\text { fitur upload. }\end{array}$ \\
\hline
\end{tabular}

Untuk melihat tanggapan responden (user) terhadap sistem yang dikembangkan, maka dilakukan survei terhadap 40 responden dengan memberikan 15 pertanyaan dengan jawaban terdiri dari tingkatan yang dapat dilihat pada tabel 4 .

Tabel 4 Pilihan Jawaban UAT

\begin{tabular}{ll}
\hline A & Sangat: \\
& Mudah/Bagus/Sesuai/Jelas/Menarik/Membantu/Bisa/Tep \\
& at/Efektif \\
B & $\begin{array}{l}\text { Mudah/Bagus/Sesuai/Jelas/Menarik/Membantu/Bisa/Tep } \\
\text { at/Efektif }\end{array}$ \\
C & Netral \\
D & Sulit/Jelek/Tidak Sesuai/Tidak Jelas/Tidak Menarik/Tidak \\
& Membantu/Tidak Tepat/Tidak Efektif \\
E & $\begin{array}{l}\text { Sangat: Sulit/Jelek/Tidak Sesuai/Tidak Jelas/Tidak } \\
\text { Menarik/Tidak Membantu/Tidak Tepat/Tidak Efektif }\end{array}$ \\
&
\end{tabular}

Tabel 5 Pertanyaan Kuesioner

\begin{tabular}{|c|c|c|c|c|c|c|c|c|}
\hline Variabel & Pertanyaan & Ax5 & Bx4 & $\begin{array}{l}\text { Nilai } \\
\text { Cx3 }\end{array}$ & Dx2 & Ex1 & Jumlah & $(\%)$ \\
\hline \multirow[t]{5}{*}{ Desain } & Apakah tampilan web ini menarik? & 29 & 11 & 0 & 0 & 0 & 189 & 94.5 \\
\hline & Apakah menu atau fitur web mudah dipahami? & 20 & 17 & 3 & 0 & 0 & 177 & 88.5 \\
\hline & $\begin{array}{l}\text { Apakah penggunaan warna tulisan dengan latar belakang } \\
\text { (background) sudah sesuai? }\end{array}$ & 27 & 12 & 1 & 0 & 0 & 186 & 93 \\
\hline & Apakah sistem monitoring pariwisata Provinisi Bali ini menarik? & 21 & 18 & 1 & 0 & 0 & 180 & 90 \\
\hline & Apakah penggunaan tulisan (font) mudah di baca? & 28 & 11 & 1 & 0 & 0 & 187 & 93.5 \\
\hline \multirow[t]{7}{*}{ Layanan } & Apakah data yang ditampilkan pada web ini mudah dipahami? & 19 & 19 & 1 & 1 & 0 & 176 & 88 \\
\hline & $\begin{array}{l}\text { Apakah dengan adanya sistem ini membantu proses monitoring } \\
\text { pariwisata Provinsi Bali? }\end{array}$ & 25 & 14 & 1 & 0 & 0 & 184 & 92 \\
\hline & $\begin{array}{l}\text { Apakah sistem ini dapat dijadikan alat bantu monitoring } \\
\text { pariwisata Provinsi Bali? }\end{array}$ & 29 & 10 & 1 & 0 & 0 & 188 & 94 \\
\hline & $\begin{array}{l}\text { Secara keseluruhan apakah penggunaan sistem ini sudah } \\
\text { memuaskan? }\end{array}$ & 15 & 19 & 6 & 0 & 0 & 169 & 84.5 \\
\hline & $\begin{array}{l}\text { Apakah adanya statistik data lewat beberapa bentuk chart } \\
\text { membantu menganalisa data? }\end{array}$ & 26 & 12 & 2 & 0 & 0 & 184 & 92 \\
\hline & $\begin{array}{l}\text { Apakah adanya fitur prediksi membantu dalam proses } \\
\text { pengambilan keputusan? }\end{array}$ & 26 & 10 & 4 & 0 & 0 & 182 & 91 \\
\hline & Apakah sistem ini sudah sesuai dengan kebutuhan? & 17 & 21 & 2 & 0 & 0 & 175 & 87.5 \\
\hline \multirow[t]{3}{*}{ Efisien } & $\begin{array}{l}\text { Apakah penggunaan sistem monitoring aktivitas pariwisata } \\
\text { Provinsi Bali ini sudah tepat sasaran? }\end{array}$ & 16 & 21 & 3 & 0 & 0 & 173 & 86.5 \\
\hline & $\begin{array}{l}\text { Apakah web ini dapat dijadikan media monitoring aktivitas } \\
\text { pariwisata Provinsi Bali? }\end{array}$ & 25 & 12 & 3 & 0 & 0 & 182 & 91 \\
\hline & Seberapa efektif penggunaan sistem ini menurut Anda? & 16 & 22 & 2 & 0 & 0 & 174 & 87 \\
\hline
\end{tabular}

Berdasarkan tabel 5 dapat dilihat bahwa jumlah nilai 40 responden (28 mahasiswa, 9 pegawai negeri/swasta, dan 3 pekerjaan lainnya) untuk pertanyaan pertama adalah 189 (94.5\%), pertanyaan kedua adalah 177 (88.5\%), pertanyaan ketiga adalah 186 (93\%), pertanyaan keempat adalah $180(90 \%)$, pertanyaan kelima adalah 187 (93.5\%), pertanyaan keenam adalah $176(88 \%)$, pertanyaan ketujuh adalah 184 (92\%), pertanyaan kedelapan adalah $188(94 \%)$, pertanyaan kesembilan adalah $169 \quad(84.5 \%)$, pertanyaan kesepuluh adalah 184 (92\%), pertanyaan kesebelas adalah $182(91 \%)$, pertanyaan kedua belas adalah $175(87.5 \%)$, pertanyaan ketiga belas adalah $173(86.5 \%)$, pertanyaan keempat belas adalah 182 
(91\%), pertanyaan kelima belas adalah 174 (87\%). Dari data di atas disimpulkan bahwa sistem yang dikembangkan mempunyai desain sistem yang menarik dan mudah dipahami, adanya beberapa bentuk chart membantu dalam menganalisis statistik data, forecasting data juga dapat dijadikan acuan dalam mengambil sebuah keputusan.

\section{KESIMPULAN}

Perancangan business intelligence dashboard untuk monitoring aktivitas pariwisata studi kasus Dinas Pariwisata Provinsi Bali dapat digunakan untuk memanajemen data dengan menggantikan pemakaian kertas menjadi media komputer serta manajemen data agar data tidak hilang begitu saja, namun digunakan sebagai acuan dalam menentukan keputusan. Berdasarkan pengujian yang telah dilakukan, sistem yang dibuat sesuai system requirements yang ditetapkan pada awal pengembangan sistem, sistem ini memiliki tampilan yang menarik, navigasi pada web mudah dipahami, data yang ditampilkan dapat dipahami, adanya sistem ini dianggap dapat membantu dalam monitoring aktivitas pariwisat Provinsi Bali, penyajian data lewat beberapa chart sangat membantu dalam menganalisis data, perhitungan prediksi juga sangat membantu sebagai pendukung dalam pengambilan keputusan. Hal ini memperlihatkan penggunaan teknologi business intelligence tidak hanya pada perusahaan namun juga dapat digunakan untuk mendukung bidang pariwisata, pemerintahan, dan layanan.

\section{DAFTAR PUSTAKA}

ARIFIN, M., 2014. Business Intelligence Untuk Customer Churn Telekomunikasi. Prosiding SNATIF, 1, pp.279-286.

AZU, H. G. M., 2014. New Approach for Determining the Smoothing Constant of a Single Exponential Smoothing Method. International Journal of Science and Technology, 3(11), pp.717-727.

BRANNON, N,. 2010. Business Intelligence and EDiscovery. Intellectual Property \& Technology Law Journal, 22(7), pp.1-5.

CIMPERMAN, R., 2006. Uat Defined: A Guide to Practical User Acceptance Testing. Addison-Wesley Professional.

CONNOLLY, T., \& Begg, C., 2015. Database Systems: A Practical Approach to Design, Implementation, and Management: Global Edition. In Science.

KAO, H. Y., YU, M. C., MASUD, M., WU, W. H., CHEN, L. J., \& WU, Y. C. J., 2016. Design and evaluation of hospital-based business intelligence system (HBIS): A foundation for design science research methodology. Computers in Human Behavior.

MAHBUB, N., PAUL, S. K., \& AZEEM, A., 2013. A neural approach to product demand forecasting. International Journal of Industrial and Systems Engineering, 15(1), pp.1-18.

MAKRIDAKIS, S., WHEELWRIGHT C, S., \& MCGEE, V. E., 1999. Metode dan Aplikasi Peramalan. In Binarupa Aksara.

MARTIADI, R. H., PUDJIANTORO, T. H., \& RENALDI, F., 2017. Pembangunan Perangkat Lunak Business Intelligence di Dinas Perhubungan Kabupaten Bandung Barat. Simetris: Jurnal Teknik Mesin, Elektro Dan Ilmu Komputer, 8(2), pp.433440.

MUSTAQBAL, M. S., FIRDAUS, R. F., \& RAHMADI, H., 2015. Pengujian Aplikasi Menggunakan Black Box Testing Boundary Value Analysis (Studi Kasus: Aplikasi Prediksi Kelulusan SNMPTN). Jurnal Ilmiah Teknologi Terapan (JITTER), 1(3), pp.31-36.

OLSZAK, C. M., \& ZIEMBA, E., 2007. Approach to building and implementing Business Intelligence systems. Interdisciplinary Journal of Information, Knowledge, and Management., 2, pp.135-148.

PRAYITNO, D., 2018. Application of Business Intelligence for Banking Performance Based on Products Analysis. International Journal of Progressive Sciences and Technologies (IJPSAT), 6(2), pp.554-569

RAFTERY, A. E., 1985. Time series analysis. In European Journal of Operational Research 20(2), pp.127-137

SETIAWAN, D. Y., HENDRAWAN, R. A., \& TYASNURITA, R., 2013. Perancangan Business Intelligence Dashboard Berbasis Web Untuk Pemantauan Tingkat Keberhasilan Pambangunan Ketenagakerjaan (Studi Kasus: Provinsi Jawa Timur). Teknik Pomits, 2(1), pp.1-6.

YOETI, O. A., 1990. Pemasaran Pariwisata. Bandung:Angkasa. 